\title{
The Significance of Metastasectomy in Patients with Metastatic Renal Cell Carcinoma in the Era of Targeted Therapy
}

\author{
Xiaoteng Yu, ${ }^{1}$ Bing Wang, ${ }^{2}$ Xuesong Li, ${ }^{1}$ Gang Lin,, Cuijian Zhang,, Yang Yang, \\ Dong Fang, ${ }^{1}$ Yi Song, ${ }^{1}$ Zhisong He, ${ }^{1}$ and Liqun $\mathrm{Zhou}^{1}$ \\ ${ }^{1}$ Department of Urology, Peking University First Hospital, Institute of Urology, National Urological Cancer Center, \\ Peking University, Beijing 100034, China \\ ${ }^{2}$ Department of Orthopedics, Peking University First Hospital, Beijing 100034, China \\ ${ }^{3}$ Department of Thoracic Surgery, Peking University First Hospital, Beijing 100034, China
}

Correspondence should be addressed to Xuesong Li; pineneedle@sina.com and Liqun Zhou; zhouliqunmail@sina.com

Received 14 June 2015; Revised 5 August 2015; Accepted 13 August 2015

Academic Editor: Andrea Minervini

Copyright (C) 2015 Xiaoteng Yu et al. This is an open access article distributed under the Creative Commons Attribution License, which permits unrestricted use, distribution, and reproduction in any medium, provided the original work is properly cited.

\begin{abstract}
Objective. To investigate the efficacy of surgery in the treatment of metastatic renal cell carcinoma (mRCC) and to identify prognostic factors. Methods. A single center retrospective study of 96 patients with mRCC from December 2004 to August 2013. Results. The median follow-up time was 45 months. Thirty-one (32.3\%) of the patients received complete resection of metastatic sites, $11(11.5 \%)$ of the patients underwent incomplete resection of metastatic sites, and $54(56.3 \%)$ of the patients received no surgery. In the univariate Kaplan-Meier analysis, the median overall survival times of the three groups were 52 months, 16 months, and 22 months, respectively $(p<0.001)$. The difference in the overall survival time was statistically significant between complete resection and no surgery groups $(\mathrm{HR}=0.43, p=0.009)$, while there was no significant difference between the incomplete metastasectomy and no surgery groups $(\mathrm{HR}=1.80, p=0.102)$. According to the multivariate Cox regression analysis, complete metastasectomy $(\mathrm{HR}=0.49, p=0.033)$, $\mathrm{T}$ stage $>3(\mathrm{HR}=1.88, p=0.015)$, disease free interval $<12$ months $(\mathrm{HR}=2.34, p=0.003)$, and multiorgan involvement $(\mathrm{HR}=2.00, p=0.011)$ were significant prognostic factors. Conclusion. In the era of targeted therapy, complete metastasectomy can improve overall survival. Complete metastasectomy, T stage $>3$, disease free interval $<12$ months, and multiorgan involvement are independent prognostic factors.
\end{abstract}

\section{Introduction}

Kidney cancer accounts for approximately $2-3 \%$ of all the adult malignancies, and the incidence is increasing [1]. Despite the advancements in early diagnosis, $20-30 \%$ of patients present with synchronous metastatic renal cell carcinoma (mRCC) [2]. Approximately one-third of patients experience disease relapse as either a local recurrence or distant metastasis, after the primary surgery for the renal tumors $[3,4]$. Metastatic renal cell carcinoma is associated with a poor prognosis and a 5-year survival rate not more than $10 \%$ [5]. Before the emergence of targeted therapy, immunotherapy was the main therapeutic option. However, a low response rate and high incidence of adverse events make this option only suitable for a specific subset of patients $[6,7]$.
Targeted drugs, such as sunitinib, sorafenib, everolimus, and bevacizumab, have improved the tumor response rate and changed the treatment algorithms of mRCC in recent years [8-10]. However, the complete response rate was rather low, and none of the drugs were curative [11, 12]. We cannot ignore the significance of metastasectomy in regard to curative intent. Although previous reports are promising, the role of metastasectomy in an era of targeted therapy is an actively researched field. Thus, we performed a retrospective analysis of 107 patients in our center to elucidate the significance of metastasectomy in the treatment of mRCC. Our main objective was to investigate the impact of metastasectomy on survival time and to identify prognostic factors related to survival. 


\section{Materials and Methods}

After ethical committee approval, a total of 130 patients with metastatic renal cell carcinoma treated in Peking University First Hospital between December 2004 and August 2013 were retrospectively included in our study. The diagnoses of renal cell carcinoma were made based on histopathological evaluations of the specimens acquired by previous nephrectomy or renal biopsy. All the 130 patients were with oligometastasis and a Karnofsky Performance Scale (KPS) not less than 80. The metastatic sites were defined by computed tomography (CT), magnetic resonance imaging (MRI), and positron emission tomography (PET) or confirmed by pathological outcomes of the metastasectomy. 11 of the 130 patients did not have previous nephrectomy and were excluded from the study. Another 23 patients were excluded due to incomplete data concerning survival time, pathology, metastatic sites, and detailed record of surgery. Among the 23 patients, 16 patients did not receive metastasectomy, 1 patient received incomplete metastasectomy, 5 patients underwent complete metastasectomy, and 1 patient lacked the detailed record of surgery. And finally we identified 96 patients for the definitive analysis.

We retrospectively collected the clinical and pathologic characteristics of the patients, including gender, age at first metastasis development, targeted therapy, pathology, diseasefree interval (DFI), sites of metastases, number of organs with metastases, and the surgical margins of the metastasectomy. The primary nephrectomy was either a partial nephrectomy or a radical nephrectomy. The different nephrectomies were decided on a case-by-case basis. The 2004 WHO classification of renal tumors was used when evaluating the pathology [13]. Complete metastasectomy was defined as resection of all the metastases, while incomplete metastasectomy was defined as resection of some but not all the metastases. The DFI was defined as the period between the primary diagnosis of the renal tumor and the first occurrence of the metastases.

After the initial treatment, there was a follow-up appointment every 6 months, during which an abdominal ultrasound, chest X-ray, or CT and a routine blood test were performed and evaluated. Also, medical histories were collected and necessary physical examinations were taken. A bone scan and MRI of the brain were used in cases of overt symptoms. 51 patients had overt symptoms indicating metastasis which were further confirmed by imaging studies. Repeat metastasectomies were indicated in 5 patients with relapse of the disease who were in otherwise good condition.

We compared clinical and pathological characteristics among complete metastasectomy, incomplete metastasectomy, and no metastasectomy groups, using Pearson's chisquare for categorical variables. The primary endpoint was overall survival (OS), which was calculated from the first metastasis development to death or the time of last follow-up. We used a Kaplan-Meier method to estimate the OS. Univariable Kaplan-Meier methods with log rank tests and univariable Cox regression methods were performed to compare the survival difference between the groups. A multivariable Cox regression model was used to identify the prognostic factors of OS. All of the statistical analyses were made using SPSS
20.0 (IBM Corporation, New York, USA), and $p$ value $<0.05$ was considered to be statistically significant.

\section{Results}

3.1. Patients Characteristics. Our study comprised 96 mRCC patients, including 78 males (81.3\%) and 18 females (18.7\%). The median age was 57 years (range: 17-79 years). All of the patients had undergone a prior nephrectomy for a primary tumor, and the majority of the patients $(75.0 \%)$ received targeted therapy. 16 patients underwent interferon as adjuvant therapy after primary nephrectomy, and 10 patients received interleukin-2, while 2 patients received chemotherapy. Clear cell carcinoma was the dominant pathology. A small percentage of the patients exhibited clear cell carcinoma with sarcomatoid dedifferentiation. Lung and bone were the most common metastatic sites. $63.5 \%$ of the patients had only one organ involvement. More than half of the patients had a relatively short DFI. For the treatment of the metastatic lesions, 31 patients received a complete resection and 11 patients underwent an incomplete resection, while 54 patients received no surgery and opted for targeted therapy. 25 patients in the complete resection group had solitary lesion. No neoadjuvant or immediate adjuvant targeted therapy was used in the metastasectomy group. Targeted therapy was only administered in case of inoperable progressive disease in this group. Detailed clinical and pathological characteristics of the patients are shown in Table 1.

The clinical and pathological differences between these groups were not significant concerning gender $(p=0.262)$, age $(p=0.953)$, clear cell carcinoma or nonclear cell carcinoma $(p=0.217)$, disease-free interval $(p=0.154)$, T stage $(p=0.979)$, grade $(p=0.155)$, and lymph node involvement $(p=0.111)$. But there were significant differences concerning multiorgan involvement or single organ involvement between these groups $(p=0.042)$ (Table 2$)$.

All of the patients in the no resection group were given targeted drugs; the efficacy evaluation showed that $1(1.8 \%)$ patient achieved complete responses (CR), 13 (24.1\%) patients reached partial responses (PR), 38 (70.4) patients experienced stable disease (SD), and 2 (3.7\%) patients developed progressive disease. Efficacy was defined according to the Response Evaluation Criteria in Solid Tumors (RECIST) criteria [14].

3.2. Overall Survival by Kaplan-Meier Analysis. The median follow-up time of the 96 patients was 45 months (range: 2-112 months). Seventy patients $(63.5 \%)$ died prior to the last follow-up. Considering that only 2 patients died of noncancer-related causes (atrial fibrillation), we decided to use overall survival as the primary endpoint. According to the Kaplan-Meier analysis, the median OS of the 96 patients was 24.0 months (95\% CI: 17.6-30.4 months) (Figure 1).

3.3. Univariable Analysis by Kaplan-Meier. The KaplanMeier univariate analysis indicated that the median OS in the complete resection, incomplete resection, and no resection groups was 52 months, 16 months, and 22 months, respectively. The difference between the groups was statistically 
TABLE 1: Clinical and pathological characteristics.

\begin{tabular}{|c|c|c|}
\hline Characteristics & Number & Percent (\%) \\
\hline Total patients & 96 & 100.0 \\
\hline \multicolumn{3}{|l|}{ Gender } \\
\hline Male & 78 & 81.3 \\
\hline Female & 18 & 18.7 \\
\hline \multicolumn{3}{|l|}{ Years $\geq 65$} \\
\hline Yes & 26 & 27.1 \\
\hline No & 70 & 72.9 \\
\hline \multicolumn{3}{|l|}{ Targeted therapy } \\
\hline Sunitinib & 35 & 36.5 \\
\hline Sorafenib & 37 & 38.5 \\
\hline No & 24 & 25.0 \\
\hline \multicolumn{3}{|l|}{ Pathology } \\
\hline Clear cell & 90 & 93.8 \\
\hline Papillary & 5 & 5.2 \\
\hline Undifferentiated & 1 & 1.0 \\
\hline \multicolumn{3}{|l|}{ Sarcomatoid dedifferentiation } \\
\hline Yes & 11 & 11.5 \\
\hline No & 85 & 88.5 \\
\hline \multicolumn{3}{|l|}{$\mathrm{T}$} \\
\hline T1-2 & 55 & 57.3 \\
\hline T3-4 & 41 & 42.7 \\
\hline \multicolumn{3}{|l|}{$\mathrm{N}$} \\
\hline N0 & 87 & 90.6 \\
\hline N1-2 & 9 & 9.4 \\
\hline \multicolumn{3}{|l|}{ G } \\
\hline G1-2 & 68 & 70.8 \\
\hline G3-4 & 28 & 29.2 \\
\hline \multicolumn{3}{|l|}{ Metastatic sites } \\
\hline Lung & 55 & 57.3 \\
\hline Bone & 39 & 40.6 \\
\hline Liver & 8 & 8.3 \\
\hline Brain & 4 & 4.2 \\
\hline Adrenal gland & 14 & 14.6 \\
\hline Retroperitoneal lymph node & 13 & 13.5 \\
\hline Supradiaphragmatic lymph node & 4 & 4.2 \\
\hline Others & 7 & 7.3 \\
\hline \multicolumn{3}{|l|}{ Metastatic organ } \\
\hline 1 & 61 & 63.5 \\
\hline$\geq 2$ & 35 & 36.5 \\
\hline \multicolumn{3}{|l|}{ Disease-free interval } \\
\hline$\leq 12$ months & 53 & 55.2 \\
\hline$>12$ months & 43 & 44.8 \\
\hline \multicolumn{3}{|l|}{ Metastasectomy } \\
\hline Complete resection & 31 & 32.3 \\
\hline Incomplete resection & 11 & 11.5 \\
\hline No resection & 54 & 56.3 \\
\hline
\end{tabular}

significant $(p=0.001)$ (Figure 2$)$. Meanwhile, T stage $\geq 3$ $(p=0.012)$, the $\leq 12$-month DFI $(p=0.000)$, and multiorgan involvement $(p=0.001)$ had adverse effects on OS

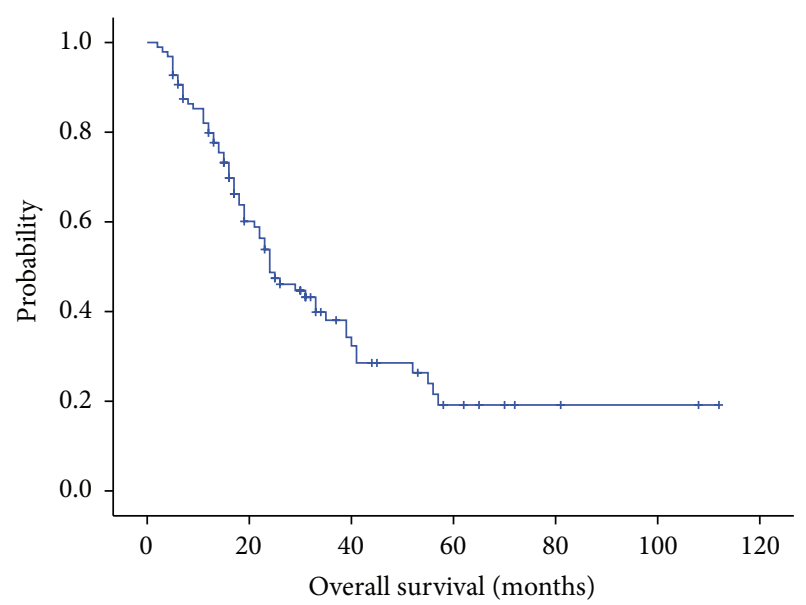

Median OS: 24.0 months (95\% CI: 17.6-30.4)

FIGURE 1: Overall survival (median OS: 24.0 months).

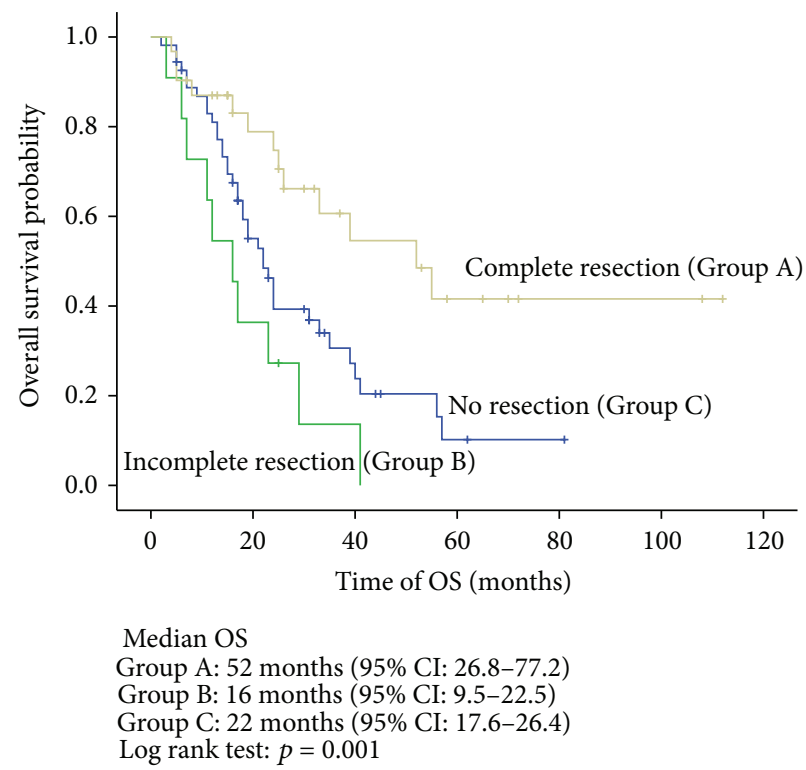

FIGURE 2: Overall survival stratified by completeness of resection (Group A: complete resection; Group B: incomplete resection; Group C: no resection).

(Figures 3-5). Other potential prognostic factors used in our analysis included gender, year, targeted therapy, pathological characteristics, lymph node involvement, and metastatic sites. However, none of these factors were statistically significant (data not shown).

Also, we performed a subgroup analysis of all the patients who underwent metastasectomy but did not show a significant difference between the targeted therapy group and nontargeted therapy group (median OS: 26 months versus 33 months, $p=0.706$ ).

3.4. Multivariable Analysis by Cox Regression. When using Cox regression univariate analysis, there was a significant difference between the complete metastasectomy and no 
TABLE 2: Difference of critical clinical and pathological characteristics between groups.

\begin{tabular}{|c|c|c|c|c|}
\hline Characteristics & $\begin{array}{c}\text { Number } \\
\text { Complete metastasectomy }\end{array}$ & $\begin{array}{c}\text { Number } \\
\text { Incomplete metastasectomy }\end{array}$ & $\begin{array}{c}\text { Number } \\
\text { No metastasectomy }\end{array}$ & $p$ value \\
\hline \multicolumn{5}{|l|}{ Gender } \\
\hline Male & 28 & 9 & 41 & \multirow{2}{*}{0.262} \\
\hline Female & 3 & 2 & 13 & \\
\hline \multicolumn{5}{|l|}{ Years } \\
\hline 65 or more & 9 & 3 & 14 & \multirow{2}{*}{0.953} \\
\hline Less than 65 & 22 & 8 & 40 & \\
\hline \multicolumn{5}{|l|}{ Pathology } \\
\hline Clear cell carcinoma & 31 & 10 & 49 & \multirow{2}{*}{0.217} \\
\hline Others & 0 & 1 & 5 & \\
\hline \multicolumn{5}{|l|}{$\mathrm{T}$} \\
\hline T1-2 & 18 & 6 & 31 & \multirow{2}{*}{0.979} \\
\hline T3-4 & 13 & 5 & 23 & \\
\hline \multicolumn{5}{|l|}{$\mathrm{N}$} \\
\hline No & 30 & 11 & 46 & \multirow{2}{*}{0.111} \\
\hline N1-2 & 1 & 0 & 8 & \\
\hline \multicolumn{5}{|l|}{ G } \\
\hline G1-2 & 18 & 8 & 42 & \multirow{2}{*}{0.155} \\
\hline G3-4 & 13 & 3 & 12 & \\
\hline \multicolumn{5}{|l|}{ DFI } \\
\hline 12 months or less & 17 & 9 & 27 & \multirow{2}{*}{0.154} \\
\hline More than 12 months & 14 & 2 & 27 & \\
\hline \multicolumn{5}{|l|}{ Metastatic organ } \\
\hline 1 & 25 & 5 & 31 & \multirow{2}{*}{$0.042^{*}$} \\
\hline$\geq 2$ & 6 & 6 & 23 & \\
\hline
\end{tabular}

${ }^{*}$ Statistically significant.

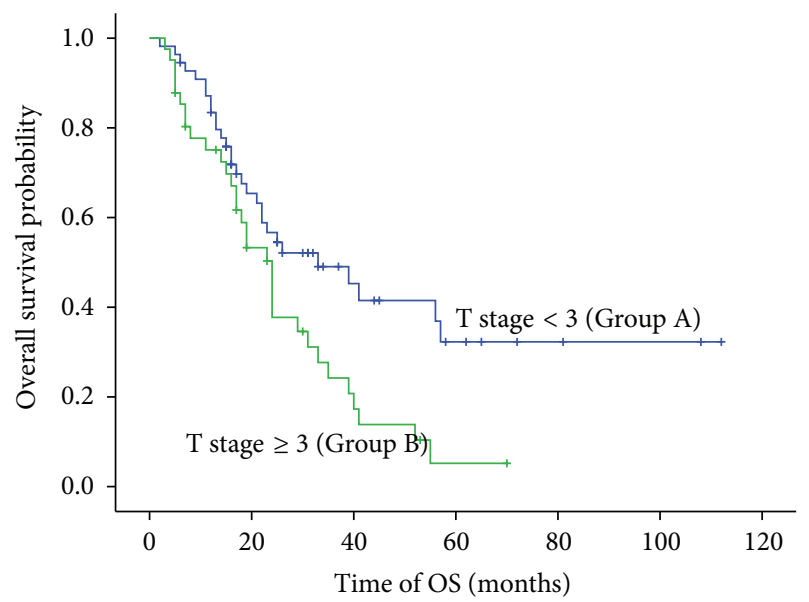

Median OS

Group A: 33 months (95\% CI: $15.8-50.2)$

Group B: 24 months (95\% CI: 19.4-28.6)

Log rank test: $p=0.012$

Figure 3: Overall survival stratified by T stage (Group A: T stage < 3; Group B: T stage $\geq 3$ ).

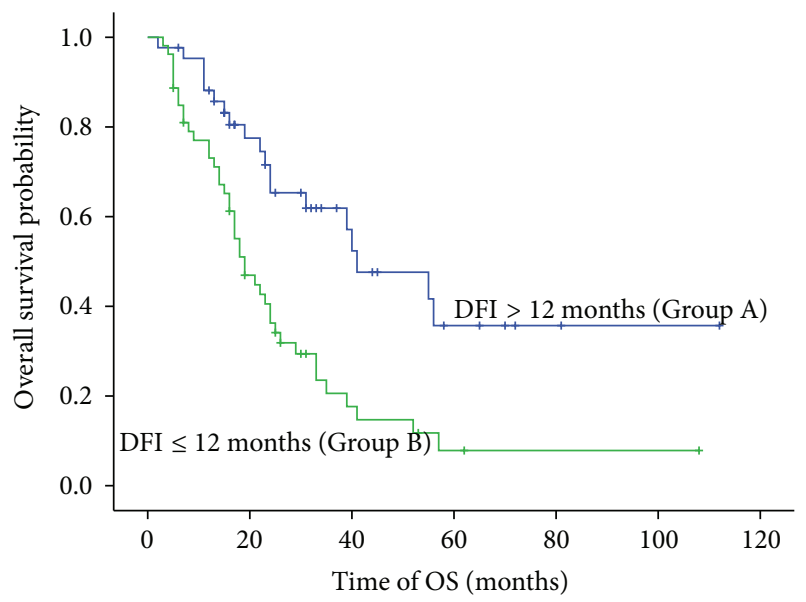

Median OS

Group A: 41 months (95\% CI: 21.5-60.5)

Group B: 19 months (95\% CI: 13.6-24.4)

Log rank test: $p=0.000$

FIGURE 4: Overall survival stratified by DFI (Group A: DFI > 12 months; Group B: DFI $\leq 12$ months.). 
TABLE 3: Univariate Cox regression analysis of prognostic factors of overall survival.

\begin{tabular}{|c|c|c|c|c|c|}
\hline \multirow{2}{*}{ Parameter } & \multicolumn{2}{|c|}{ Patients } & \multicolumn{2}{|c|}{ Overall survival } & \multirow{2}{*}{$p$ value } \\
\hline & $n$ & Percent \% & Median, mo & HR, 95\% CI & \\
\hline Overall & 96 & 100 & 24 & & \\
\hline \multicolumn{6}{|l|}{ Gender } \\
\hline Male & 78 & 81.3 & 25 & $1.25(0.66-2.37)$ & 0.490 \\
\hline Female & 18 & 18.7 & 23 & Reference & \\
\hline \multicolumn{6}{|l|}{ Years $\geq 65$} \\
\hline Yes & 26 & 27.1 & 23 & $1.34(0.78-2.32)$ & 0.293 \\
\hline No & 70 & 72.9 & 24 & Reference & \\
\hline \multicolumn{6}{|l|}{ Targeted therapy } \\
\hline Yes & 72 & 75.0 & 24 & $1.29(0.71-2.35)$ & 0.406 \\
\hline No & 24 & 25.0 & 33 & Reference & \\
\hline \multicolumn{6}{|l|}{ Clear cell carcinoma } \\
\hline Yes & 90 & 93.8 & 25 & $0.56(0.22-1.41)$ & 0.218 \\
\hline No & 6 & 6.2 & 17 & Reference & \\
\hline \multicolumn{6}{|c|}{ Sarcomatoid dedifferentiation } \\
\hline Yes & 11 & 11.5 & 13 & $1.74(0.85-3.53)$ & 0.129 \\
\hline No & 85 & 88.5 & 25 & Reference & \\
\hline \multicolumn{6}{|l|}{ T stage } \\
\hline $\mathrm{T} \geq 3$ & 41 & 42.7 & 24 & $1.88(1.13-3.13)$ & $0.015^{*}$ \\
\hline $\mathrm{T}<3$ & 55 & 57.3 & 33 & Reference & \\
\hline \multicolumn{6}{|l|}{ G grade } \\
\hline $\mathrm{G} \geq 3$ & 28 & 29.2 & 24 & $1.39(0.81-2.37)$ & 0.231 \\
\hline $\mathrm{G}<3$ & 68 & 70.8 & 26 & Reference & \\
\hline \multicolumn{6}{|l|}{$\mathrm{N}$} \\
\hline N1-2 & 9 & 9.4 & 24 & $0.83(0.36-1.93)$ & 0.660 \\
\hline N0 & 87 & 90.6 & 24 & Reference & \\
\hline \multicolumn{6}{|l|}{ Lung metastasis } \\
\hline Yes & 55 & 57.3 & 24 & $1.60(0.94-2.73)$ & 0.086 \\
\hline No & 41 & 42.7 & 33 & Reference & \\
\hline \multicolumn{6}{|l|}{ Bone metastasis } \\
\hline Yes & 39 & 40.6 & 29 & $0.95(0.57-1.58)$ & 0.846 \\
\hline No & 57 & 59.4 & 24 & Reference & \\
\hline \multicolumn{6}{|c|}{ Number of metastatic organs } \\
\hline 1 & 61 & 63.5 & 31 & Reference & \\
\hline$\geq 2$ & 35 & 36.5 & 17 & $2.25(1.34-3.78)$ & $0.002^{*}$ \\
\hline \multicolumn{6}{|l|}{ Disease-free interval } \\
\hline$\leq 12$ months & 53 & 55.2 & 19 & $2.59(1.50-4.48)$ & $0.001^{*}$ \\
\hline$>12$ months & 43 & 44.8 & 41 & Reference & \\
\hline \multicolumn{6}{|l|}{ Metastasectomy } \\
\hline Complete resection & 31 & 32.3 & 52 & $0.43(0.23-0.81)$ & $0.009^{*}$ \\
\hline Incomplete resection & 11 & 11.5 & 16 & $1.80(0.89-3.62)$ & 0.102 \\
\hline No resection & 54 & 56.3 & 22 & Reference & \\
\hline
\end{tabular}

${ }^{*}$ Statistically significant.

resection groups $(\mathrm{HR}=0.43, p=0.009)$. With this analysis, there was no significant difference between the incomplete metastasectomy and no resection groups $(\mathrm{HR}=1.80, p=$ $0.102)$. Also, $\mathrm{T}$ stage $\geq 3(\mathrm{HR}=1.88, p=0.015), \mathrm{DFI} \leq 12$ months $(\mathrm{HR}=2.59, p=0.001)$, and multiorgan involvement $(\mathrm{HR}=2.25, p=0.002)$ were associated with poor OS (Table 3).
Based on the multivariate Cox regression analysis, a complete metastasectomy was still a favorable predictor of OS $(\mathrm{HR}=0.49, p=0.033)$, while an incomplete metastasectomy seemed to decrease the overall survival compared with no resection for metastatic sites, though the influence was not statistically significant $(\mathrm{HR}=1.35, p=0.418)$. The influence of T stage $\geq 3(\mathrm{HR}=1.89, p=0.018)$, the $\mathrm{DFI} \leq 12$ months 
TABLE 4: Multivariate Cox regression analysis of prognostic factors of overall survival.

\begin{tabular}{lccc}
\hline Covariates & HR & $p$ value & 95\% CI \\
\hline No resection & Reference & & \\
$\quad$ Incomplete resection & 1.35 & 0.418 & $0.65-2.77$ \\
$\quad$ Complete resection & 0.49 & 0.033 & $0.25-0.94$ \\
T stage $\geq 3$ (Yes versus No) & 1.89 & 0.018 & $1.11-3.20$ \\
Multiorgan metastasis (Yes versus No) & 2.00 & 0.011 & $1.17-3.41$ \\
DFI $\leq 12$ months (Yes versus No) & 2.34 & 0.003 & $1.33-4.12$ \\
\hline
\end{tabular}

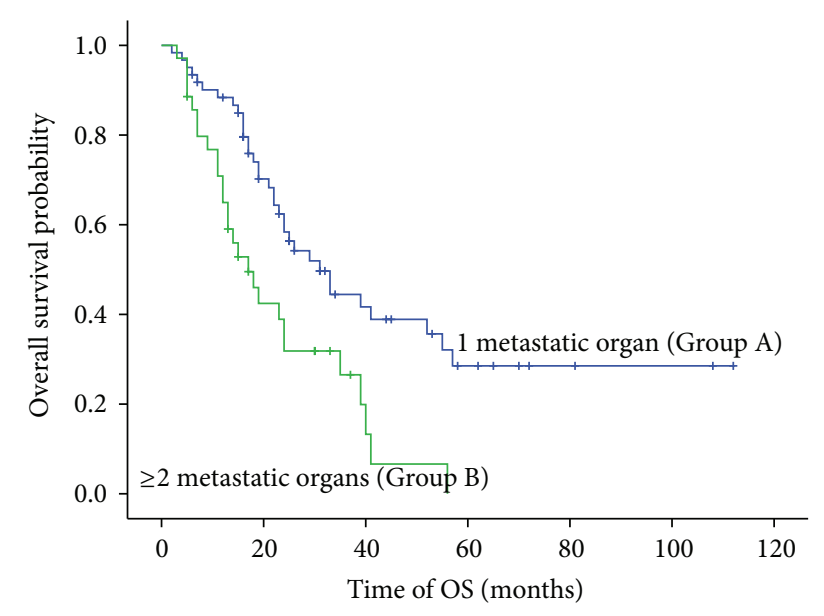

Median OS

Group A: 31 months (95\% CI: 21.8-40.1)

Group B: 17 months (95\% CI: 10.7-23.3)

Log rank test: $p=0.001$

FIGURE 5: Overall survival stratified by number of metastatic sites (Group A: 1 metastatic organ; Group B: $\geq 2$ metastatic organs).

$(\mathrm{HR}=2.34, p=0.003)$, and multiorgan involvement $(\mathrm{HR}=$ 2.00, $p=0.011$ ) on OS was still present (Table 4).

\section{Discussion}

The robust clinical responses of targeted therapy have revitalized the treatment of metastatic renal cell carcinoma. However, the long-term survival for patients with renal cell carcinoma remains low. Surgery as part of a multimodal treatment of mRCC is a potential way to improve the longterm survival. Prospective randomized trials have proven the importance of cytoreductive nephrectomy in the cytokine era [15]. The literature in recent years also favors cytoreductive nephrectomy to increase the overall survival in this era of targeted therapy $[16,17]$.

In 1939, Barney and Churchill reported the first metastasectomy performed on a 55-year-old woman with a solitary pulmonary metastasis. After the resection, the prognosis was quite promising. Since then, increasing evidence has shown that resection of metastatic sites benefits the OS or the 5-year survival rate in appropriately selected patients. Alt et al. investigated $887 \mathrm{mRCC}$ patients and found better CSS in patients with a complete metastasectomy ( 4.8 years versus 1.3 years, $p<0.001)$. Furthermore, a subgroup analysis of the lung-only metastases or non-lung-only metastases groups and synchronous or asynchronous multiple metastases groups also showed an improvement in the CSS and the 5 -year survival rate in favor of a complete metastasectomy [18]. Naito et al. reviewed $566 \mathrm{mRCC}$ patients in a multicenter retrospective study and reported a median OS time of 109.8 months and 31.9 months in the complete metastasectomy and incomplete metastasectomy groups, respectively, which was statistically significant. The authors also demonstrated that incomplete resection of metastases adversely affected the OS using multivariate analysis [19].

Our results concerning the impact of metastasectomy on OS were consistent with previous studies. The data in the present study showed that the OS in the complete metastasectomy, incomplete metastasectomy, and no resection groups was 52,16 , and 22 months, respectively. The results showed better OS in favor of a complete resection of metastases compared with no resection. Meanwhile, incomplete metastasectomy was associated with worse OS. Although the difference was not statistically significant, the OS in the incomplete resection group was shorter than in the no resection group.

Several factors may have led to the decreased OS in the incomplete resection and no resection groups. First, the tumors in the incomplete resection group have more metastatic sites than the other two groups, making a complete resection of all the metastatic sites even impossible. Second, the tumors in the incomplete resection group may have been more invasive, which made a complete resection rather difficult during the surgery. Third, some of the patients who underwent a metastasectomy were distressed by pain or loss of function; therefore, surgery in these situations was not performed with a curative intent but with palliative intent and resulted in an incomplete resection.

Despite the lack of clear improvement in OS and possible postoperative complications, metastasectomy may help to ameliorate pain and improve functional recovery. Thus, an incomplete resection has a role in improving quality of life if the metastatic sites are in weight-bearing bones, causes severe pain, or compromises neurological function [20]. We recommend performing a metastasectomy only after a full evaluation, including determining the resectability of the tumor and the patients' personal condition.

In addition to resectability, several potential prognostic factors should be evaluated. There is no consensus regarding the standardized tools that help assure the best candidates for a metastasectomy, and most of the evidence is based on retrospective studies. In a 64-patient study, Hofmann et al. reported that in patients receiving a pulmonary metastasectomy the synchronous metastases had a worse 5-year survival rate compared with metachronous metastases $(0 \%$ versus $43.7 \%$ ), respectively, suggesting that the DFI may have an impact on the survival of patients who underwent metastasectomy. However, the sample size was relatively small, and the metastases were exclusively in the lung [21]. Tosco et al. performed a multicenter retrospective analysis of 109 patients and identified four independent adverse factors on prognosis: $T$ stage of the primary tumor $\geq 3$, Fuhrman grade $\geq 3$, disease-free interval $\leq 12$ months, and multiorgan metastases [22]. The data in our study were in line with 
previous reports and also indicated that $\mathrm{T}$ stage $\geq 3$ ( $\mathrm{HR}=$ 1.88, $p=0.015)$, disease-free interval $\leq 12$ months $(\mathrm{HR}=$ $2.34, p=0.003)$, and multiorgan involvement $(\mathrm{HR}=2.00$, $p=0.011)$ were associated with poor OS.

The primary limitation of our study is that it is a retrospective study. There were biases we were unable to avoid. Patients selected for complete metastasectomy may have had better ECOG PS, lower risk MSKCC [23], or Heng group [24] and therefore had better survival. Some of the patients who underwent an incomplete resection were only attempting to improve their quality of life by alleviating their pain or recovering function. In these cases, the procedure was not intended to be curative. Also, the number of patients who underwent incomplete metastasectomy was small, and the results merit further investigation. Unfortunately, the lack of data regarding these aspects made this analysis difficult to carry out. Due to incomplete records on the specific targeted therapy usage, such as duration of medication or drug dosage, we were unable to incorporate detailed information in our analysis despite their potential effects on survival.

In conclusion, our study shows that complete metastasectomy can improve OS in the era of targeted therapy, whereas incomplete resection did not. A $\mathrm{T}$ stage $\geq 3$, DFI $\leq 12$ months, and multiorgan involvement are independent adverse prognostic factors for OS.

\section{Conflict of Interests}

The authors declare that there is no conflict of interests regarding the publication of this paper.

\section{Authors' Contribution}

Xiaoteng Yu and Bing Wang contribute equally to this study.

\section{Acknowledgment}

The authors must thank Professor Jose A. Karam for helping to revise and polish the paper.

\section{References}

[1] R. Siegel, D. Naishadham, and A. Jemal, "Cancer statistics, 2013," CA Cancer Journal for Clinicians, vol. 63, no. 1, pp. 11-30, 2013.

[2] M. Staehler, N. Haseke, G. Schoeppler, T. Stadler, C. Gratzke, and C. G. Stief, "Modern therapeutic approaches in metastatic renal cell carcinoma," EAU-EBU Update Series, vol. 5, no. 1, pp. 26-37, 2007.

[3] H. T. Cohen and F. J. McGovern, "Renal-cell carcinoma," The New England Journal of Medicine, vol. 353, no. 23, pp. 24772490, 2005.

[4] G. H. J. Mickisch, A. Garin, H. van Poppel, L. de Prijck, and R. Sylvester, "Radical nephrectomy plus interferon-alfabased immunotherapy compared with interferon alfa alone in metastatic renal-cell carcinoma: a randomised trial," The Lancet, vol. 358, no. 9286, pp. 966-970, 2001.

[5] B. I. Rini, S. C. Campbell, and B. Escudier, "Renal cell carcinoma," The Lancet, vol. 373, no. 9669, pp. 1119-1132, 2009.
[6] C. Coppin, F. Porzsolt, A. Awa, J. Kumpf, A. Coldman, and T. Wilt, "Immunotherapy for advanced renal cell cancer," The Cochrane Database of Systematic Reviews, no. 1, Article ID CD001425, 2005.

[7] R. M. Bukowshi, "Cytokine therapy for metastatic renal cell carcinoma," Seminars in Urologic Oncology, vol. 19, no. 2, pp. 148-154, 2001.

[8] R. J. Motzer, B. I. Rini, R. M. Bukowski et al., "Sunitinib in patients with metastatic renal cell carcinoma," The Journal of the American Medical Association, vol. 295, no. 21, pp. 2516-2524, 2006.

[9] B. Escudier, T. Eisen, W. M. Stadler et al., "Sorafenib in advanced clear-cell renal-cell carcinoma," The New England Journal of Medicine, vol. 356, no. 2, pp. 125-134, 2007.

[10] B. Escudier, A. Pluzanska, P. Koralewski et al., "Bevacizumab plus interferon alfa-2a for treatment of metastatic renal cell carcinoma: a randomised, double-blind phase III trial," The Lancet, vol. 370, no. 9605, pp. 2103-2111, 2007.

[11] B. I. Rini, "Vascular endothelial growth factor-targeted therapy in renal cell carcinoma: current status and future directions," Clinical Cancer Research, vol. 13, no. 4, pp. 1098-1106, 2007.

[12] B. I. Rini, "Vascular endothelial growth factor-targeted therapy in metastatic renal cell carcinoma," Cancer, vol. 115, no. 10, supplement, pp. 2306-2312, 2009.

[13] A. Lopez-Beltran, M. Scarpelli, R. Montironi, and Z. Kirkali, "2004 WHO classification of the renal tumors of the adults," European Urology, vol. 49, no. 5, pp. 798-805, 2006.

[14] F. Duffaud and P. Therasse, "New guidelines to evaluate the response to treatment in solid tumors," Bulletin du Cancer, vol. 87, no. 12, pp. 881-886, 2000.

[15] R. C. Flanigan, G. Mickisch, R. Sylvester, C. Tangen, H. Van Poppel, and E. D. Crawford, "Cytoreductive nephrectomy in patients with metastatic renal cancer: a combined analysis," The Journal of Urology, vol. 171, no. 3, pp. 1071-1076, 2004.

[16] L. Zini, U. Capitanio, P. Perrotte et al., "Population-based assessment of survival after cytoreductive nephrectomy versus no surgery in patients with metastatic renal cell carcinoma," Urology, vol. 73, no. 2, pp. 342-346, 2009.

[17] M. R. Abern, E. Scosyrev, M. Tsivian, E. M. Messing, T. J. Polascik, and A. Z. Dudek, "Survival of patients undergoing cytoreductive surgery for metastatic renal cell carcinoma in the targeted-therapy era," Anticancer Research, vol. 34, no. 5, pp. 2405-2412, 2014.

[18] A. L. Alt, S. A. Boorjian, C. M. Lohse, B. A. Costello, B. C. Leibovich, and M. L. Blute, "Survival after complete surgical resection of multiple metastases from renal cell carcinoma," Cancer, vol. 117, no. 13, pp. 2873-2882, 2011.

[19] S. Naito, H. Kinoshita, T. Kondo et al., "Prognostic factors of patients with metastatic renal cell carcinoma with removed metastases: a multicenter study of 556 patients," Urology, vol. 82, no. 4, pp. 846-851, 2013.

[20] M. Ruutu, P. Bono, and K. Taari, "Resection of renal cell cancer metastases: where do we stand in 2008?" European Urology Supplements, vol. 7, no. 5, pp. 436-442, 2008.

[21] H.-S. Hofmann, H. Neef, K. Krohe, P. Andreev, and R.-E. Silber, "Prognostic factors and survival after pulmonary resection of metastatic renal cell carcinoma," European Urology, vol. 48, no. 1, pp. 77-81, 2005.

[22] L. Tosco, H. Van Poppel, B. Frea, G. Gregoraci, and S. Joniau, "Survival and impact of clinical prognostic factors in surgically treated metastatic renal cell carcinoma," European Urology, vol. 63, no. 4, pp. 646-652, 2013. 
[23] R. J. Motzer, J. Bacik, L. H. Schwartz et al., "Prognostic factors for survival in previously treated patients with metastatic renal cell carcinoma," Journal of Clinical Oncology, vol. 22, no. 3, pp. 454-463, 2004.

[24] J. J. Ko, W. Xie, N. Kroeger et al., "The International Metastatic Renal Cell Carcinoma Database Consortium model as a prognostic tool in patients with metastatic renal cell carcinoma previously treated with first-line targeted therapy: a populationbased study," The Lancet Oncology, vol. 16, no. 3, pp. 293-300, 2015. 


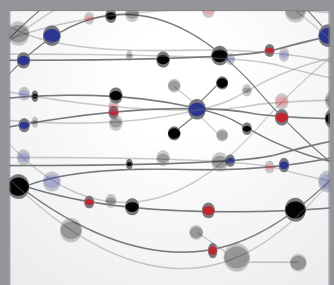

The Scientific World Journal
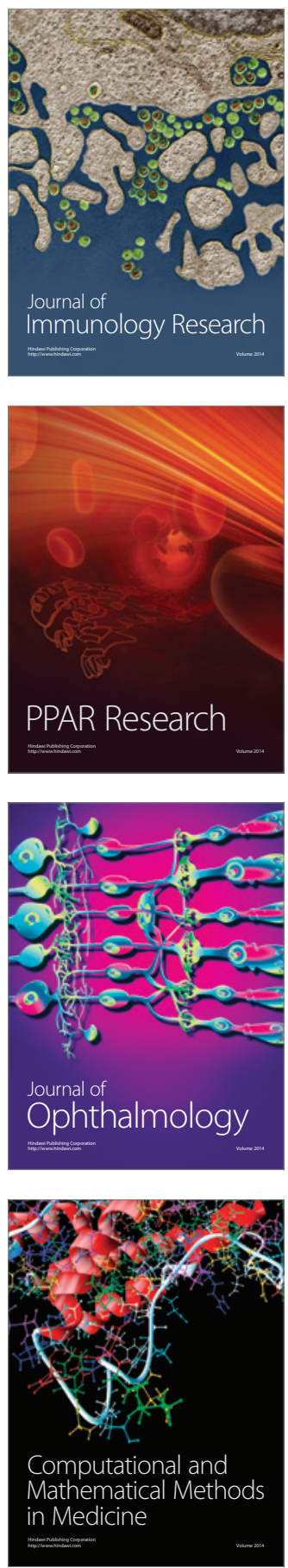

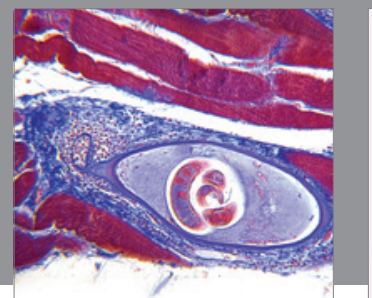

Gastroenterology

Research and Practice
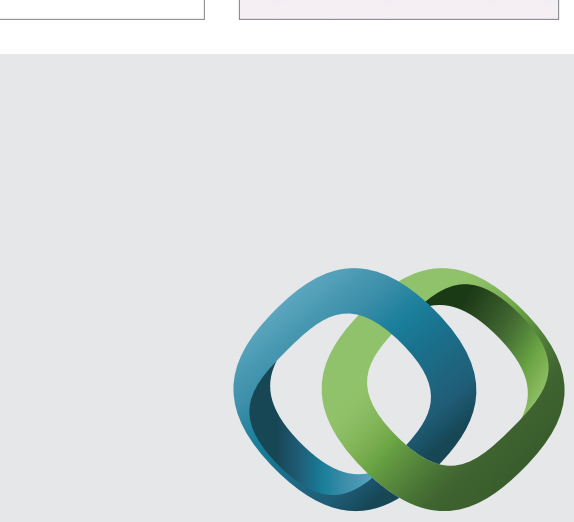

\section{Hindawi}

Submit your manuscripts at

http://www.hindawi.com
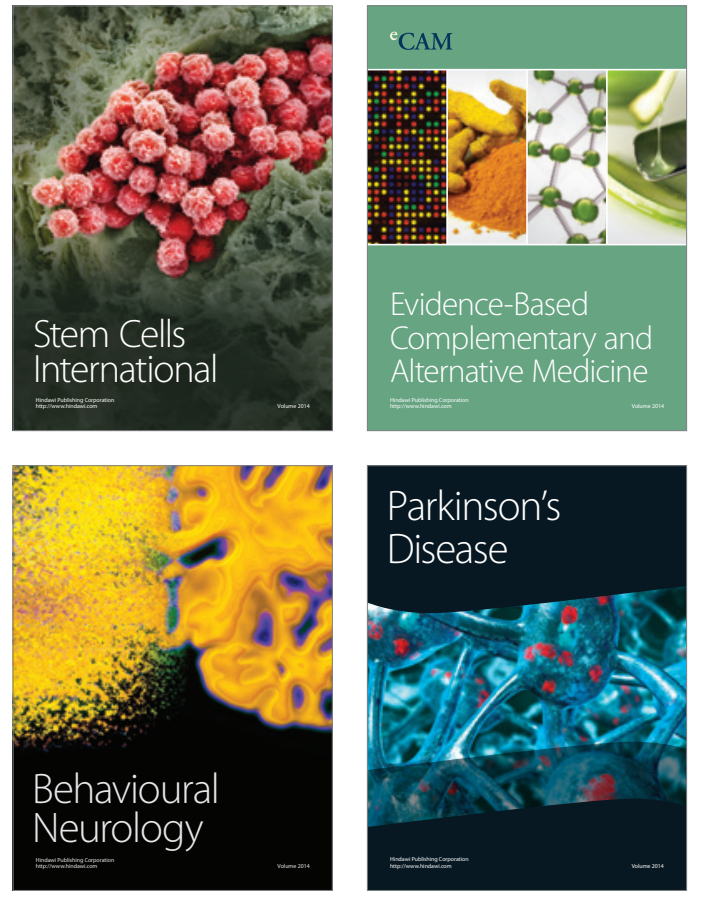
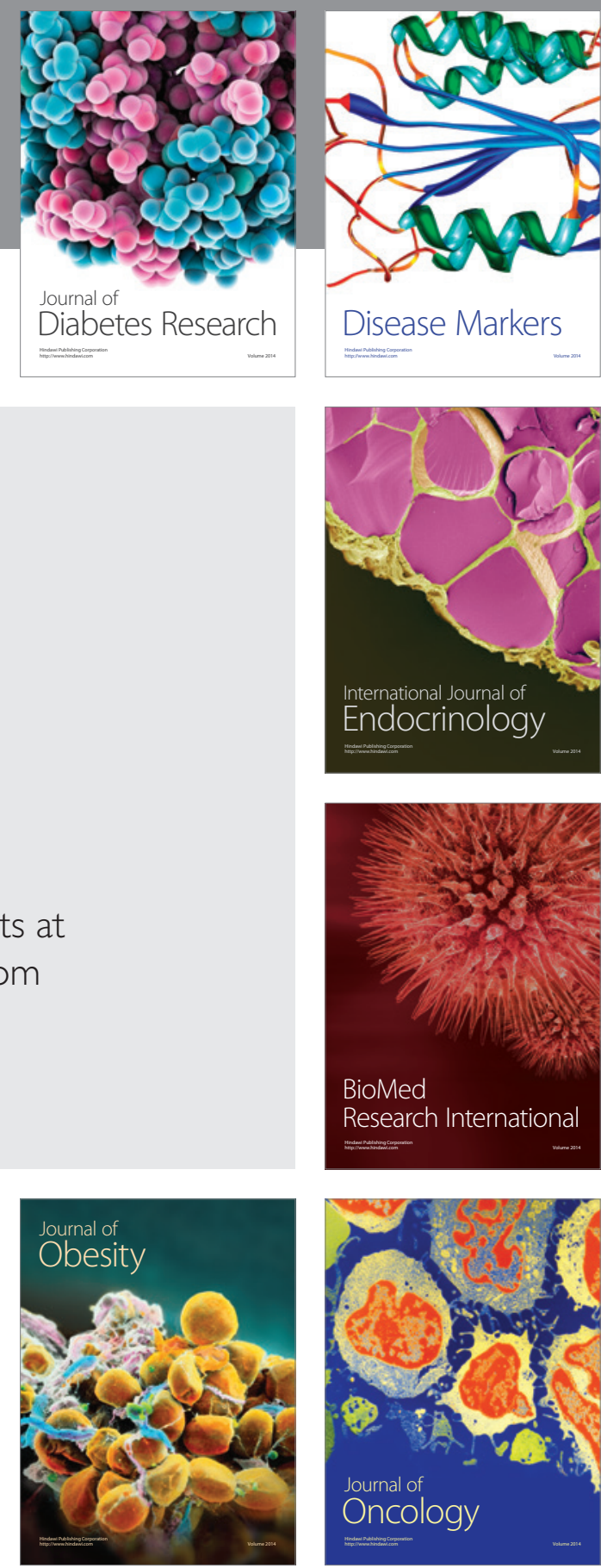

Disease Markers
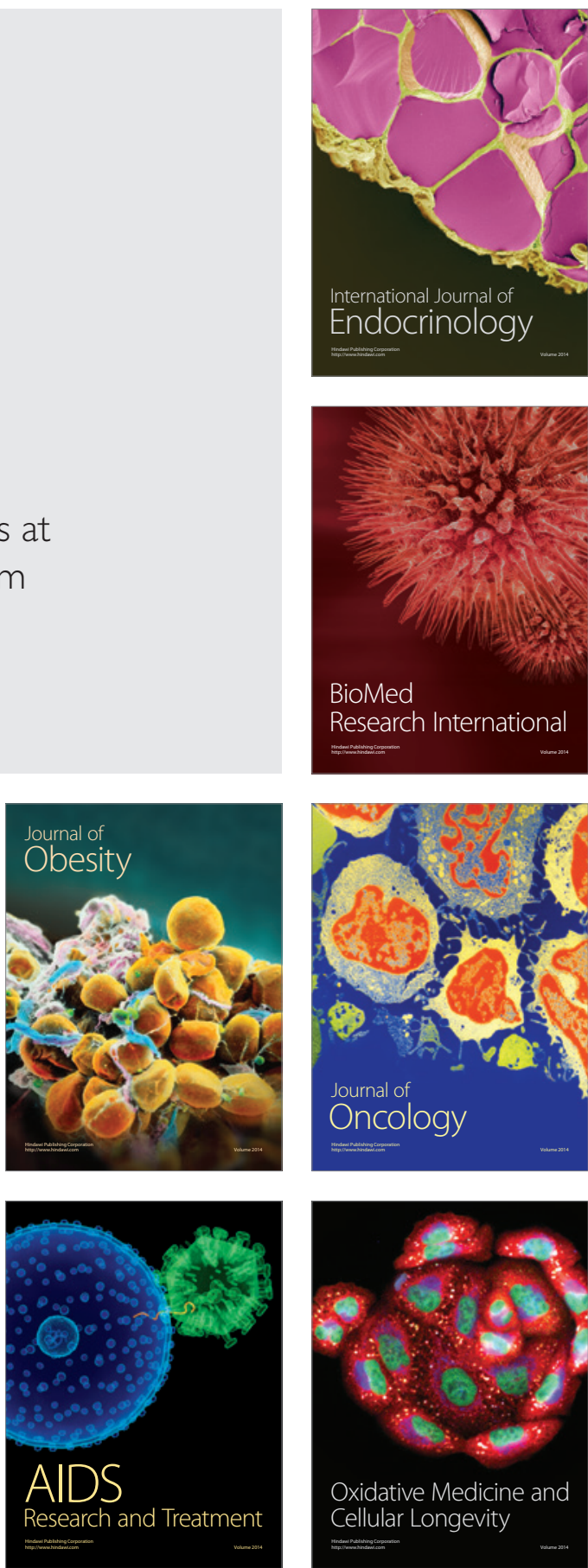